\title{
GEOSCOPE Station Noise Levels
}

\author{
by Eléonore Stutzmann, Geneviève Roult, and Luciana Astiz
}

\begin{abstract}
The noise level at GEOSCOPE seismograph stations operating in 1995 has been studied in order to quantify the quality of stations for periods ranging from 0.2 to $8000 \mathrm{sec}$. The power spectral density curves presented in this article are a useful tool for selecting stations as a function of signal-to-noise ratio in the frequency band of interest.

Seismic-noise level is the lowest for continental stations in the entire frequency band. It is similarly low at most coastal stations (stations located less than $150 \mathrm{~km}$ away from the coast). Finally, the noise level is low for island stations at long periods but increases significantly for periods smaller than 20 seconds, and in particular in the period range of the microseismic peak.

The noise level on horizontal components varies, in most stations, as a function of local time for periods greater than $20 \mathrm{sec}$, being higher during the day than during the night. Only stations located in cold areas with little daily temperature variations and stations installed in a long tunnel do not display these daily variations.

There is no seasonal variations of short-period noise (periods less than $5 \mathrm{sec}$ ). For some continental stations, we observe variations in the amplitude of the 7-sec microseismic peak during the year. For all three components, the peak amplitude is higher and shifted toward longer periods in fall and winter than in spring and summer. This phenomenon can be explained by the increase of the number and the size of oceanic storms in fall and winter. Long-period seismic noise (periods greater than $30 \mathrm{sec}$ ) also varies for some stations as a function of the season; however, no systematic characteristics have been observed.
\end{abstract}

\section{Introduction}

The objective of global seismic networks, like GEOSCOPE or IRIS, is to provide a uniform coverage of the Earth with good quality broadband stations. The installation of about 150 broadband stations on continents and islands worldwide covers most easily accessible areas. The next step is to improve Earth coverage by installing ocean bottom stations (e.g., Suyehiro et al., 1992; Montagner et al., 1994a, 1994b; Beauduin et al., 1996a; Bradley et al., 1997; Collins et al., 1998; Laske, 1998; Romanowicz et al., 1998) and also in improving the data quality. Many studies of the Earth's internal structure, earthquakes sources, and monitoring of the Comprehensive Test Ban Treaty could be improved if the noise level could be decreased.

Seismic noise has been extensively studied in the past. Relations between storms, sea waves, and seismic noise have been reported by many authors. Already in the 19th century, Bertelli emphasized a correlation between the signal recorded in Florence by a Galileo pendulum (known as a tromometer) and barometric lows, and he suspected the influence of coastal sea waves (Bernard, 1990). A significant improvement in the understanding of the noise origin was Longuet-Higgins (1950) in which he explained the micro- seismic peak (the high noise level around $14 \mathrm{sec}$ of period) as the coupling of oceanic stationary waves with seismic surface waves at the ocean bottom. The relation between microseismic noise and storms or hurricanes has also been extensively investigated for the purpose of locating storms (a review can be found in the special issue edited by Hjortenberg and Nikolaev, 1990) and the noise source area (e.g., Friedrich et al., 1998).

A good quantification and understanding of the seismic noise is the first step to reduce noise level on seismic data. The high coherence between pressure and seismic signals in the seismic period band is well known and has been used for both land and ocean bottom data. Crawford et al. (1991) developed a technique that uses the coherence between ocean bottom seismic data and local pressure changes under the loading of long-period ocean waves to study crustal structure under the station. On the other hand, Zürn and Widmer (1995) and Beauduin et al. (1996b) have shown that the noise level on land stations can be decreased by deconvolving seismic data with pressure data.

We have studied the noise level at GEOSCOPE stations in order to quantify the quality of stations for periods ranging 
from 0.2 to $8000 \mathrm{sec}$. The power spectral density curves presented here are a useful tool for selecting stations as a function of signal-to-noise ratio in the frequency band of interest. The noise level of the different stations is studied as a function of local time, season, and particular conditions at the stations.

\section{Stations Description}

In 1995, the GEOSCOPE network consisted of 23 threecomponent seismic stations with digital recording in a broad frequency band (Montagner et al. , 1998; Roult and Montagner, 1999; Roult et al., 1999). Complete information on the equipment at the stations, sensors, and acquisition systems can be found in Morand and Roult (1996) and on the Web at http://geoscope.ipgp.jussieu.fr.

Figure 1 shows the location of all stations, operating in 1995, that are used in this study. The technical installations are similar for all stations but the local conditions differ from one station to another. All stations but two (KOG and AIS) were equipped in 1995 with three-component Streckeisen STS1 sensors (Wielandt and Streckeisen, 1982). The three STS1 sensors of all stations are installed on a glass plate which is put on a 2-cm-thick sand bed. Vertical components are covered by a permalloy shielding and set in vacuum. Horizontal sensors are set in light vacuum to prevent oxidation of the sensors. The three-component STS1 sensors are covered with an aluminum shielding, a glass bell and a Styrofoam box covered with aluminum to protect them against fast changes in temperature and air flow (Roult et al., 1999). Horizontal components are only set in a light vacuum to prevent large noise arising from tilt as a result of the bending of the glass baseplate in response to the changes in pressure between the vacuum and the sand layer.

The two STS2 stations (KOG and AIS) are put directly on the concrete pillar and covered by a Styrofoam box.

Table 1 summarizes the location and altitude of the sta- tions and describes each site in terms of installation, sensor depth, geology of the underlying ground, and ground contact under the seismometer. Environmental conditions are given with humidity and temperature variations. It is also noted whether the station is located on an island, near the coast (less than $150 \mathrm{~km}$ ), or on the continent. These station characteristics are responsible for the variable data quality. In the last section the effect of these different parameters is evaluated.

\section{Seismic Noise Analysis}

In order to determine the characteristic noise level at GEOSCOPE stations, we have used a large dataset of noise sequences, homogeneously distributed from different times of the day and the year. The data sequences are selected so that no earthquake of magnitude 5.5 or greater is present in the data. The time sequence rejected after an earthquake depends on the magnitude (6 hours for magnitudes 5.5-6.0, 12 hours for magnitudes 6.0-7.0, and 48 hours for magnitudes greater than 7.0). The Harvard centroid moment tensor catalog of global seismicity has been used to remove events. The three channels, very broadband $(\mathrm{BH}$, sampling rate of $20 \mathrm{sps}$ ), long period (LH, sampling rate of $1 \mathrm{sps}$ ), and very long period ( $\mathrm{VH}$, sampling rate of $0.1 \mathrm{sps}$ ) are treated separately in order to study the period band $0.2-8000 \mathrm{sec}$. The data treatment has been adapted from a NEST package provided by L. Astiz from the IRIS DMC.

The robust power spectral density estimate has been computed using the method of Chave et al. (1987). Data are windowed using prolate tapers of Thomson (1977a, 1977b). Time windows are selected so that they overlap by $50 \%$. Each time series is prewhitened and its Fourier transform is computed and smoothed. The energy spectrum is then computed over all data windows by using the median $\left(L_{1}\right.$ norm) instead of a simple mean ( $L_{2}$ norm). An iterative algorithm is used in order to eliminate small local earthquakes or in-

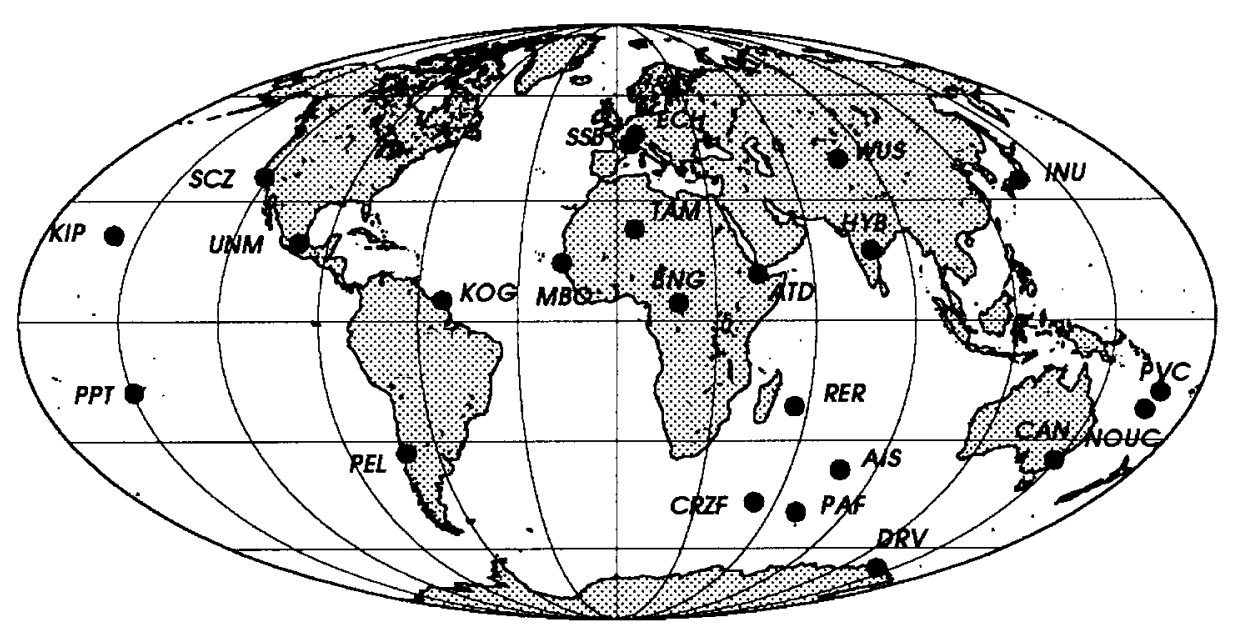

Figure 1. The GEOSCOPE network as in 1995. 


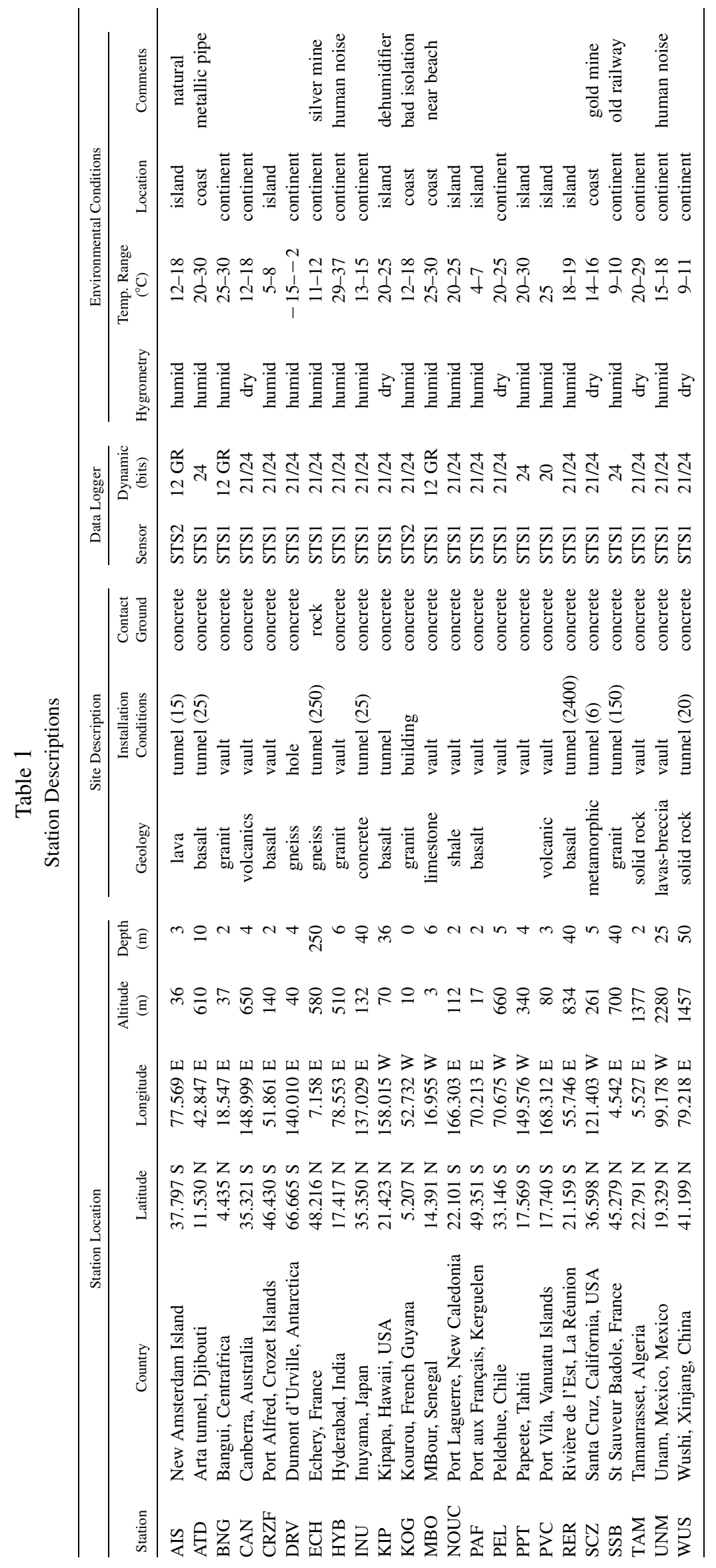


strumental noise (e.g., glitches or wrong samples) so long as they do not exceed $20 \%$ of the time windows (see Appendix $F$ in IRIS, 1995). Finally, the power spectral density is deconvolved from the instrumental response and converted into decibels $(\mathrm{dB})$ with respect to acceleration $\left(\mathrm{m} / \mathrm{s}^{2}\right)^{2} / \mathrm{Hz}$.

\section{Seismic Noise Characterization}

Broadband instruments enable us to characterize the noise in the whole period band from thousands of seconds to tens of $\mathrm{Hz}$. A very low noise level is obtained at the station TAM, located in Tamanrasset, Algeria. Figure 2 shows the TAM power spectral density estimated over the year 1995, for the three components, vertical, north-south, and eastwest. Similar curves for the other GEOSCOPE stations can be found in the appendix. The vertical component noise level of station TAM is very low and close to the low noise model. Hereafter it is described as a function of period.

For periods shorter than $1 \mathrm{sec}$, wind turbulence and human activities are the principal causes of noise. They decrease with increasing period and have no more effect at periods longer than approximately $1 \mathrm{sec}$ where a noise minimum is reached.

For periods greater than $1 \mathrm{sec}$, the noise level increases and the large noise peak around 7 seconds is the well known microseismic peak, or double-frequency peak. It is characterized by a gentle slope for periods shorter than $7 \mathrm{sec}$ and a steep slope for periods longer than $7 \mathrm{sec}$. A correlation between this peak and oceanic waves (wind waves and swell) associated with storms has long been established (e.g., Gutenberg, 1931; Ramirez, 1940). Bernard (1938) observed that the period of the microseismic peak is half of the period of these oceanic waves. Longuet-Higgins (1950) demonstrated how oceanic waves travelling in opposite directions create stationary waves at half of the period of the source waves that interact to couple energy into elastic waves, essentially Rayleigh waves. The highest period microseisms are due to very large storms and the steep slope of the peak at longer period is due to the rarity of oceanic storms with periods higher than $20 \mathrm{sec}$. The gentle slope of the microseismic peak at shorter period is due to the fact that the amplitude of oceanic waves saturates at short periods and that the attenuation of Rayleigh waves within the Earth increases with decreasing period (Pierson and Moskowitz, 1963; McCreery et al., 1993; Webb, 1998).

The noise peak observed around $14 \mathrm{sec}$, called the single-frequency peak, has a smaller amplitude than the doublefrequency peak. Storms over oceans are also at the origin of this peak but the process is different. In this case, oceanic waves striking the coast induce a direct transfer of their energy into elastic waves (Rayleigh waves) through nonlinear coupling of waves and bathymetry (Hasselmann, 1963).

The noise minimum in the period range $15-40 \mathrm{sec}$ is called the noise notch (Webb, 1998). On the vertical component, we observe two clear seismic noise minima, around
$40 \mathrm{sec}$ and $400 \mathrm{sec}$. The noise level increases again significantly for periods longer than $40 \mathrm{sec}$ on horizontal components and for periods greater than a few hundreds of seconds on the vertical component.

Sorrells (1971) and Sorrells et al. (1971) showed that atmospheric perturbations can be responsible for noise levels in the period band 20-100 sec, with different mechanisms for vertical and horizontal components. Local atmospheric pressure changes produce a static loading of the ground, which generates Earth motions. These ground movements are the principal sources of noise on the vertical component. Their horizontal amplitudes are small but they generate tilts of the ground that produce noise on the horizontal components regardless of the rock type. This effect can be substantially reduced by placing the seismometers at depth (Sorrells et al., 1971).

At still longer period, Müller and Zürn (1983) showed that the seismic noise is due to gravitational attraction changes. They observed a small but abrupt change in gravity induced by a local pressure perturbation during the passage of cold fronts. A variation of the air pressure changes the gravitational attraction of the sensor mass by the atmosphere and also the acceleration of the ground, which generates seismic noise. Zürn and Widmer (1995) and Beauduin et al. (1996b) showed that this long-period noise can be decreased by deconvolving seismic data with pressure data.

In this section we have described the natural sources of noise. It is clear that there are other sources of noise and some of a station's noise level may also contain contributions from noise induced by the sensor or by some aspects of the sensor installation.

\section{Seasonal Variations of Seismic Noise}

Seasonal variations of seismic noise are computed by averaging power spectral density over quarters for the year 1995. They are presented in Figure 3 at station INU in Japan for the three components. In the northern hemisphere (such as station INU) the green and blue curves correspond approximately to fall and winter and the pink and red curves correspond to spring and summer. We observe a variation of the amplitude and dominant period of the microseismic peak around $7 \mathrm{sec}$. In fall and winter, the amplitude of the noise is higher and the dominant peak period is shifted toward longer periods. In spring and summer, the amplitude is lower with a maximum at shorter periods. These variations are the consequences of an increase of the intensity of storms in the Pacific in autumn and winter. The increase in amplitude means that the number of storms is increasing and the shift of the dominant period toward long periods is due to an increase of large storms with respect to the rest of the year. This seasonal variation of the microseismic peak is only observed at some GEOSCOPE stations (ECH, HYB, INU, SSB), which are all continental stations with a low-noise level. 


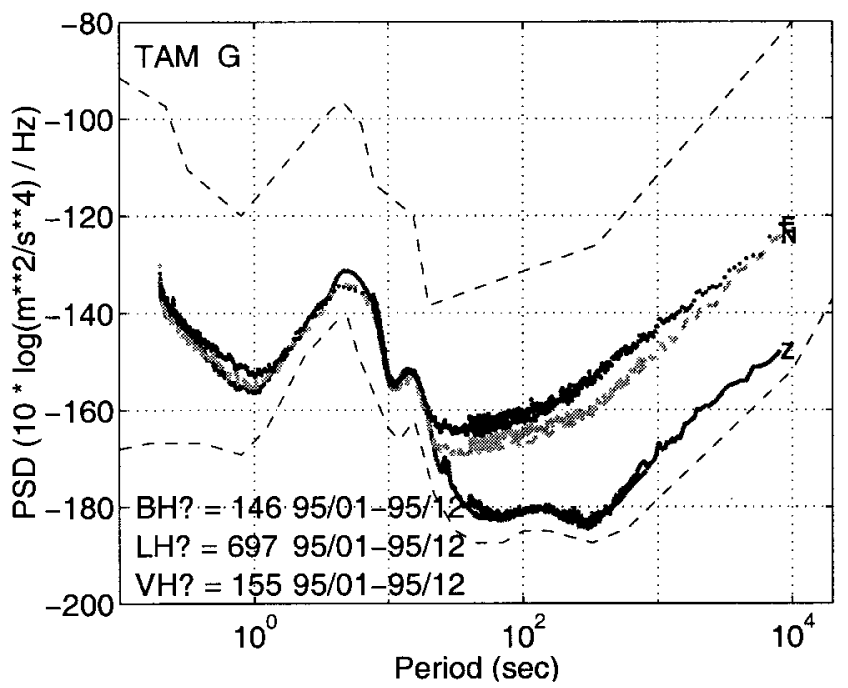

Figure 2. Station TAM power spectral density of seismic noise estimated over data from the year 1995 for the three components, vertical $(\mathrm{Z})$ in dark gray solid line, north-south $(\mathrm{N})$ in light gray dashed line, and east-west (E) in black dotted line. The number of time windows used is written next to the corresponding channel. The lower and upper dash curves are the low (LNM) and high (HNM) noise models of Peterson (1993).

\section{Diurnal Variations of Seismic Noise}

Diurnal variations of seismic noise are computed by averaging power spectral density over periods of 6 hours of local time. They are plotted on Figure 4 for the station TAM. Blue and green curves correspond to local nighttime hours (0-6 $\mathrm{h}$ and 18-24 h), whereas pink and red curves correspond to local daytime hours (6-12 $\mathrm{h}$ and $12-18 \mathrm{~h})$. On the vertical component, seismic-noise level remains constant during the day except for periods shorter than $1 \mathrm{sec}$, where seismic noise is slightly higher during the day than at night. The station is located in the suburb of Tamanrasset, and the increase of seismic noise during the day is the result of human activity. This short-period-noise variation is not observed on horizontal components. On the other hand, horizontal seismic noise varies at long period-between 30 and $500 \mathrm{sec}$ - as a function of local time. Seismic noise is higher during the day and lower at night. The installation of temperature and pressure sensors next to the seismometer should enable a better characterization of the origin of these variations.

Similar diurnal long period variations of noise are observed at most GEOSCOPE stations. Only six stations have a noise level that remains stable during the day. Three of them, CRZF, DRV, and PAF are located at high latitude in the southern hemisphere, where the annual temperature is less than $10^{\circ} \mathrm{C}$ and where the maritime climate causes little daily temperature fluctuation. The three other stations are ECH and SSB, located in France, and RER, in Reunion Island. These are the only stations located at the end of long tunnels (more than $100 \mathrm{~m}$ ) and station ECH is installed deeper than any other station (250 $\mathrm{m}$ depth).

\section{Comparison of All GEOSCOPE Stations}

In order to compare seismic noise at all GEOSCOPE stations, we have separated stations into three groups: continental, island, and coastal. We define the "coastal stations" as those located less than $150 \mathrm{~km}$ from the coast.

\section{Continental Stations}

Continental stations (Fig. 5) have the lowest seismic noise in the whole period band. The vertical component noise

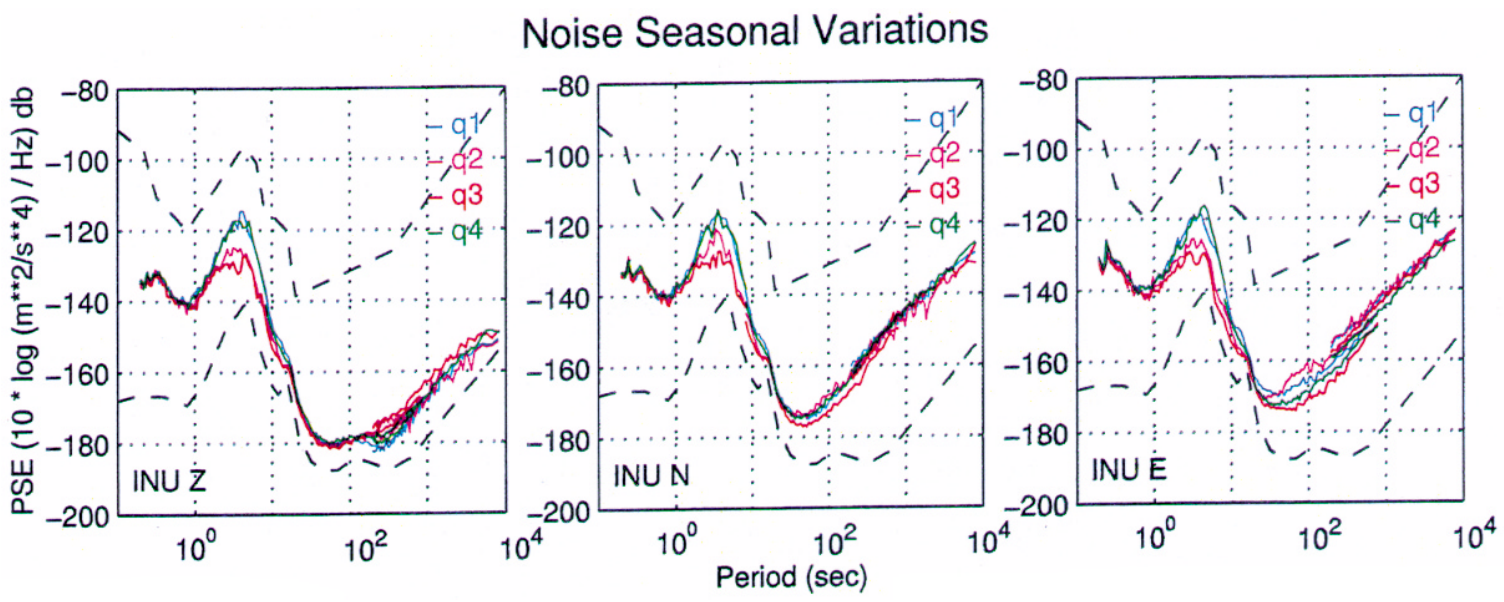

Figure 3. Seasonal variations of the seismic noise at the station INU in Japan for the three components $(\mathrm{Z}, \mathrm{N}, \mathrm{E})$, indicated in the lower left corner of each plot. Term windows are from January to March (q1, in blue), from April to June (q2, in pink), 


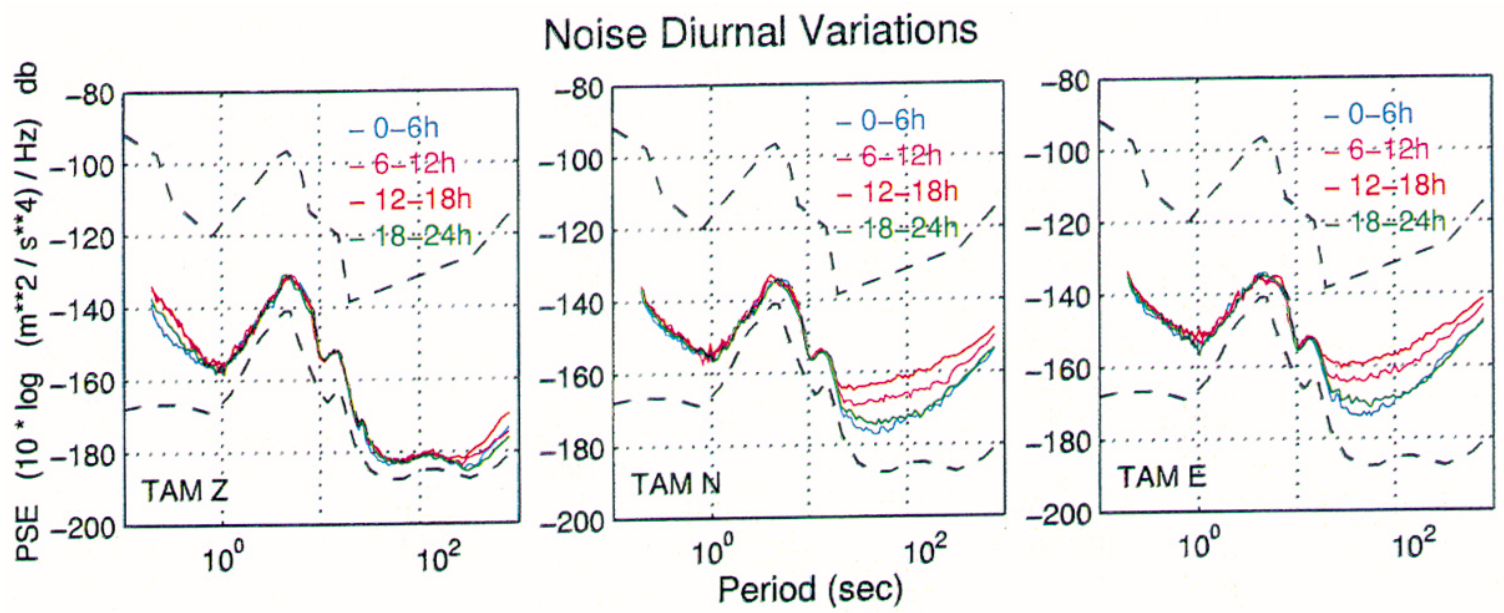

Figure 4. Diurnal variations of seismic noise as a function of period for each of the components $(\mathrm{Z}, \mathrm{N}, \mathrm{E})$, indicated in the lower left corner of each plot. Local time windows are 0-6 hours (blue), 6-12 hours (pink), 12-18 hours (red), and 18-24 hours (green).

\section{Continental Stations}

bng can drv ech hyb inu pel ssb tam unm wus
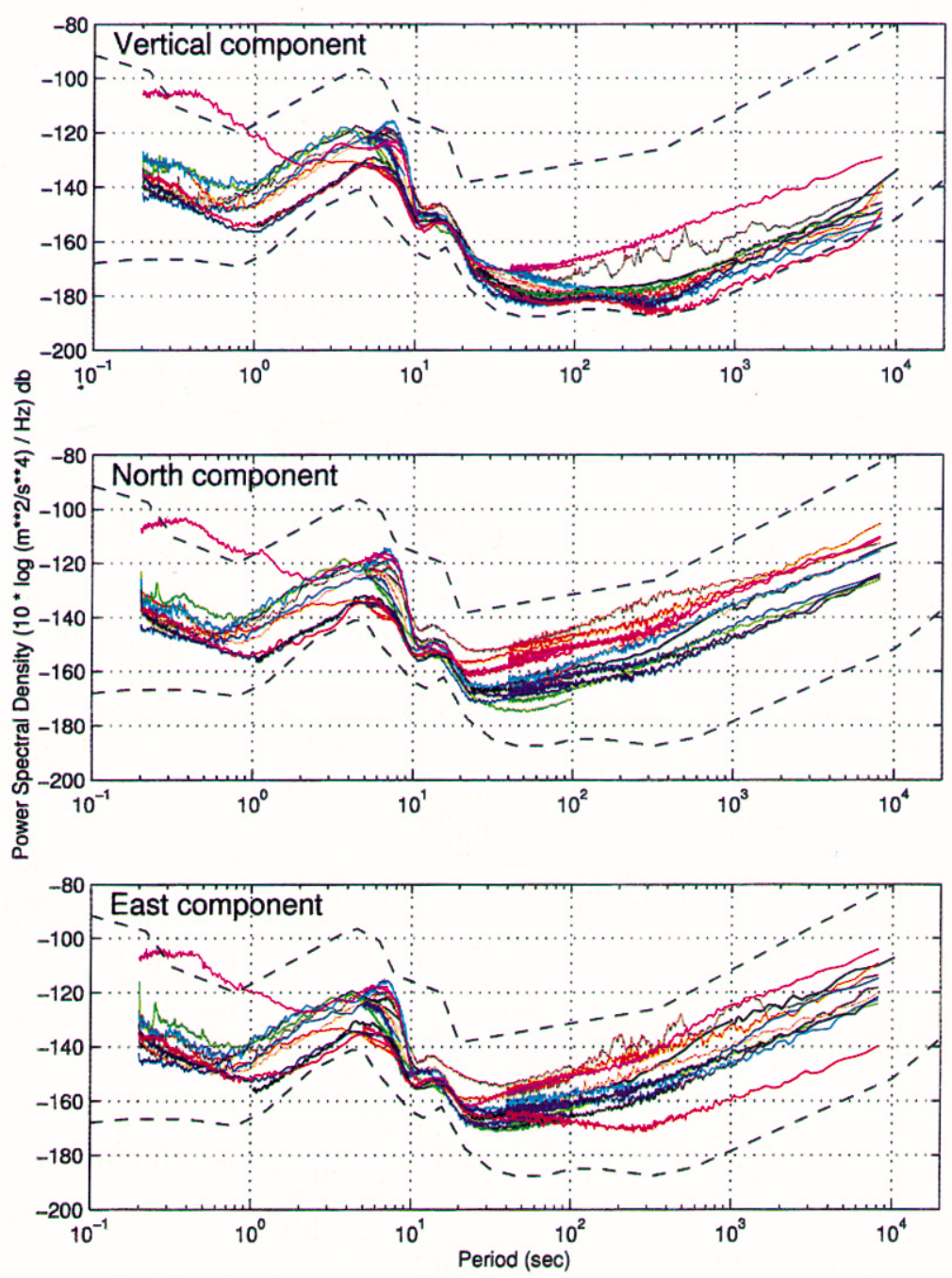

Figure 5. Power spectral density estimated over noise data from the year 1995 for the three components (vertical, top; north-south, middle; and east-west, bottom) of all continental GEOSCOPE stations. 
level is close to the low noise model of Peterson (1993) for periods greater than $20 \mathrm{sec}$ and is similar over all the stations except UNM. There is no significant decrease of long-period seismic noise by installing the station at depth. Indeed, ECH is at a depth of $250 \mathrm{~m}$ below the surface and its seismicnoise level is higher than the noise at other stations. We observe no significant variation of noise level with humidity and annual temperature variations. Long-period seismic noise on the horizontal components is higher than on the vertical component. It is generally similar on both horizontal components except for WUS station where there is a difference of more than $20 \mathrm{~dB}$ between $\mathrm{E}-\mathrm{W}$ and $\mathrm{N}-\mathrm{S}$ components, which is probably due to an instrumentation problem.
At shorter periods (below $20 \mathrm{sec}$ ), the noise level at continental stations can vary by $20 \mathrm{~dB}$ from one station to another. The stations DRV, INU, PEL, and CAN have the highest noise level. These stations are close to the Pacific Ocean. Stations ECH, SSB, which are close to the Atlantic Ocean, and HYB, which is close to the Indian Ocean, have an intermediate noise level. Finally, stations TAM and WUS, which are far from any ocean, have the lowest noise level. This result is consistent across the three components. Seismic noise in the period band 1-20 sec is the result of wind and storms over oceans and locally, and therefore we can conclude that the wind level is higher in the vicinity of the Pacific Ocean than near the Atlantic or Indian Ocean. This

\section{Insular stations}

ais crzf kip nouc paf ppt pvc rer
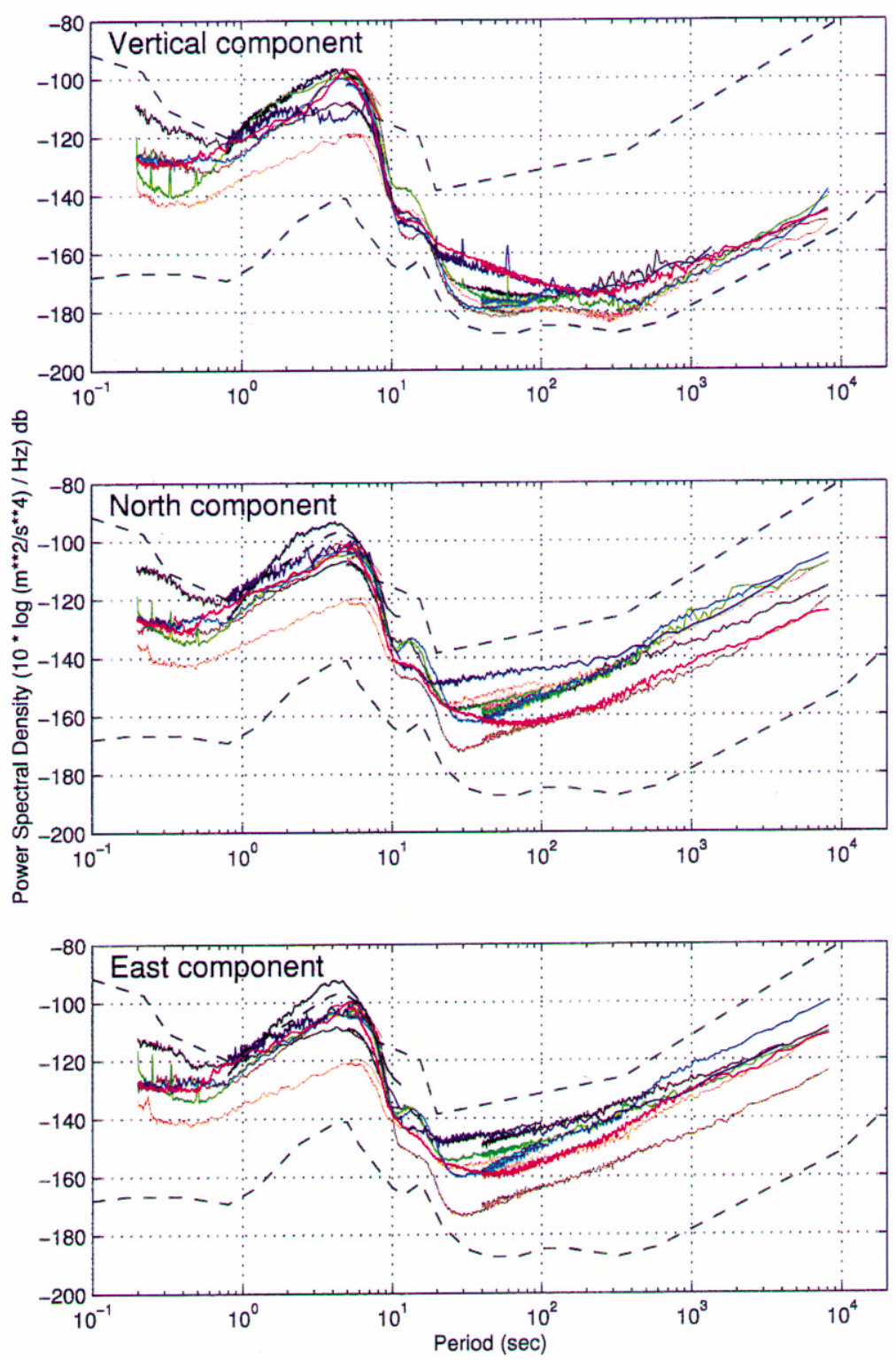

Figure 6. Power spectral density estimated over noise data from the year 1995 for the three components (vertical, top; north-south, middle; and east-west, bottom) of all island GEOSCOPE stations. The name of the station is written above the plots in the same color as the corresponding curves. 
result is well known by meteorologists and can be seen on maps of average wind speed (Webb, 1998).

Station UNM has a high noise level over the entire period band. This station is located in the city of Mexico (in the University). The human activity of this very big city can easily explain short-period noise. This station is close to both Atlantic and Pacific oceans, which are responsible for the microseismic peak noise level. The station is installed in a lava flow on the edge of a sedimentary basin and the long period noise is probably due to temperature and atmospheric variations, which are quite large in this area.

\section{Island Stations}

Island stations (Fig. 6) have a long-period (greater than $20 \mathrm{sec}$ ) seismic-noise level similar to continental stations, that is, very low on the vertical component and intermediate on the horizontal components. On the other hand, noise level for periods shorter than $20 \mathrm{sec}$ is much higher, reflecting the fact that island stations are more sensitive to oceanic storms, because Rayleigh waves arrive at the stations before being attenuated by a long propagation in the Earth to the station. All stations but KIP have a similar very high noise level for periods lower than $20 \mathrm{sec}$. These stations are all located at high latitudes in the southern hemisphere either in Indian or Pacific Ocean, in areas well known for their storms. Ice field cracks can also explain some part of short-period noise for some of these stations (e.g., DRV), which are close to glaciers and/or frozen ocean.

\section{Coastal Stations}

Coastal stations (Fig. 7) are located on a continent but less than $150 \mathrm{~km}$ from the coast. Stations SCZ and ATD have a seismic noise level similar to continental stations, whereas station MBO and KOG have a high noise level. Station MBO

\section{Coastal Stations}

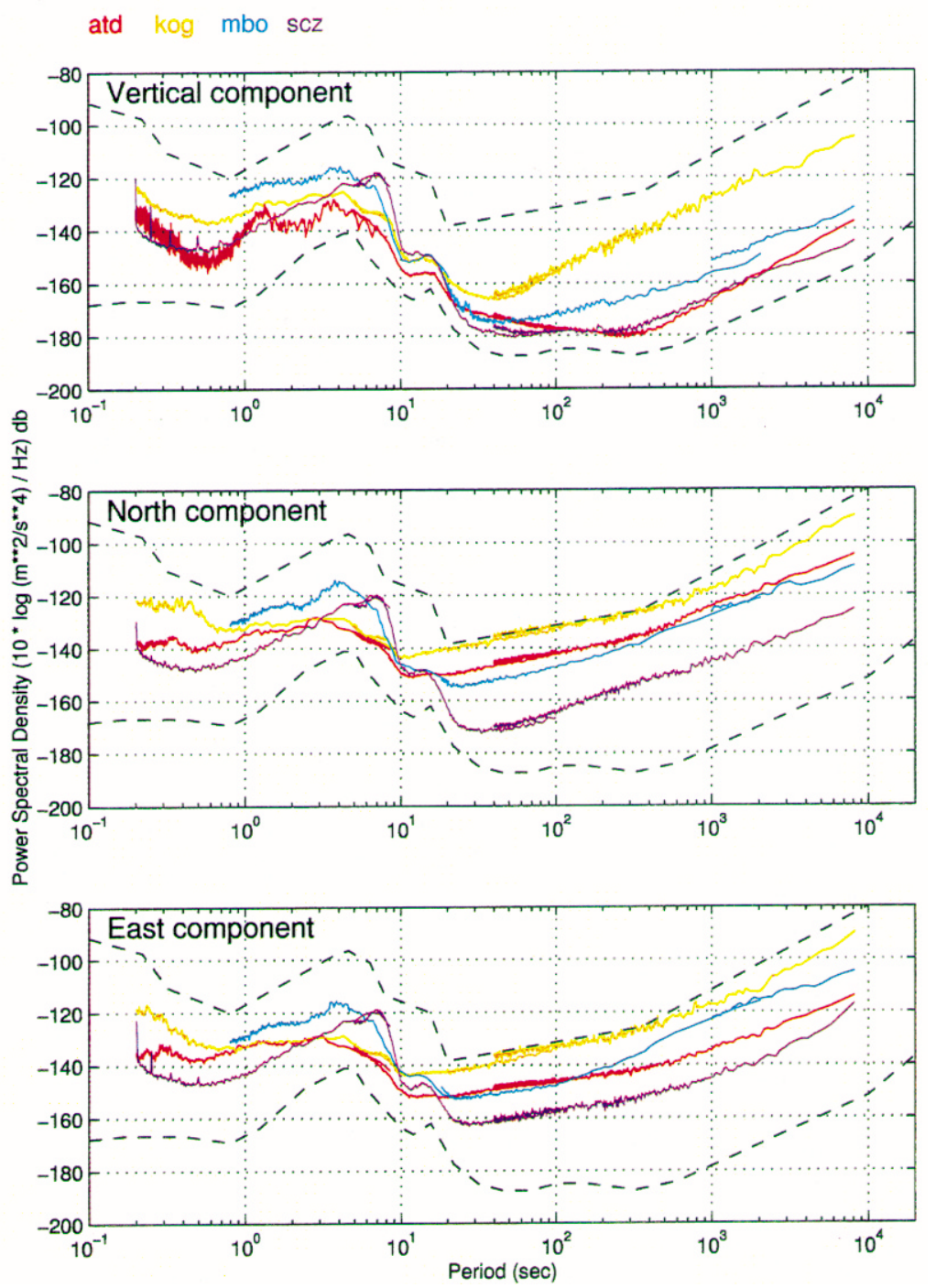

Figure 7. Power spectral density estimated over noise data from the year 1995 for the three components (vertical, top; north-south, middle; and east-west, bottom) of all coastal GEOSCOPE stations. 
has a 12-bit resolution datalogger. Station KOG is known to be poorly insulated and is installed in a concrete vault at ground level without any protection against atmospheric perturbation. This station is equipped with a STS2 seismometer, whereas most of the other stations are equipped with a STS1 seismometer. This difference may explain some part of their noise level, since the second station with a STS2 seismometer is AIS, which also has a high noise level.

\section{Conclusion}

The seismic noise level of GEOSCOPE stations operating in 1995 has been studied to quantify the quality of stations. The power spectral density curves presented in this article are a useful tool for selecting stations as a function of signal-to-noise ratio in the frequency band of interest.

Seismic noise level is the lowest at continental stations. Most coastal stations have a noise level similar or slightly higher than continental stations. Island stations have a similar low noise level at long period but a higher noise level at periods shorter than 20 seconds, and more particularly in the period range of the microseismic peaks.

Local time variations in seismic noise level on horizontal components are observed in most stations for periods longer than $20 \mathrm{sec}$. The noise level is higher during the day (between 6 a.m. and 6 p.m.) than during the night. Installing the station at a depth of 40-50 m below the surface does not attenuate daily noise variations. Only six stations show no diurnal noise variations. Three of them, CRZF, DRV, and PAF, are located at high latitude in the southern hemisphere, that is, in cold areas where annual temperature is less than $10^{\circ} \mathrm{C}$ and where there is little daily temperature fluctuation. The three other stations (ECH and SSB, located in France, and RER, in Reunion Island) are the only stations located at the end of long tunnels.

There is no systematic seasonal variations of shortperiod seismic noise (periods less than $7 \mathrm{sec}$ ). However, for some continental stations (ECH, HYB, INU, SCZ, SBB, and WUS) we observe variations of the amplitude of the 7-sec microseismic peak during the year. On all three components, the peak amplitude is higher and shifted toward longer periods in autumn and winter than in spring and summer. This phenomenon can be explained by the increase of the number and the amplitude of oceanic storms in autumn and winter. For some stations, long period seismic noise (periods greater than $30 \mathrm{sec}$ ) also varies as a function of the season but no systematic characteristic has been observed.

In future GEOSCOPE stations, the systematic installation of temperature and pressure sensors will enable to better quantify the influence of the environment on seismic noise at a particular station. These data may also be used to reduce the noise level of seismic data, especially at very long periods.

\section{Acknowledgments}

We thank our colleagues of the Technical Division of INSU in St. Maur, of EOST in Strasbourg, of ORSTOM in Bondy for providing the data and the operators in TAAF-ORSTOM stations of the southern hemisphere and Africa. We thank Michel Morand for many discussions on the stations installation and Wayne Crawford for reading this article. We appreciated the comments from the reviewer, Gary Holcomb, and the editor, Richard Aster. We also thank Philippe Lognonné, Jean-Paul Montagner, and Jean-François Karzcewski for discussions. This is IPGP Contribution No. 1675.

\section{References}

Beauduin, R., P. Lognonné, J. P. Montagner, S. Cacho, J. F. Karczewski, and M. Morand (1996a). The effects of the atmospheric pressure changes on seismic signal or how to improve the quality of a station, Bull. Seism. Soc. Am. 86, 1760-1769.

Beauduin, R., J. P. Montagner, and J. F. Karczewski (1996b). Time evolution of broadband seismic noise during the French pilot experiment OFM/SISMOBS, Geophys. Res. Lett. 23, 2995-2998.

Bernard, P. (1938). L'agitation microseismique au Japon, Ann. Phys. Globe France outre-mer 5-29, 135-136.

Bernard, P. (1990). Historical sketch of microseisms from past to future, Phys. Earth Planet. Interiors 63, 145-150.

Bradley, C. R., R. A. Dorman, L. M. Stephen, and J. A. Orcutt (1997). Very low frequency $(0.2-10.0 \mathrm{~Hz})$ seismoacoustic noise below the seafloor, J. Geophys. Res. 102, 11703-11718.

Chave, A. D., D. J. Thomson, and M. E. Ander (1987). On the robust estimation of power spectra, coherence and transfer functions, J. Geophys. Res. 92, 633-648.

Collins, J. A., F. A. Vernon, R. Stephen, K. Peal, J. Hildebrand, and F. Spiess (1998). Relative performance of the borehole, surficially buried and sea floor seismographs on the ocean seismic network pilot experiment: frequency-domain results, Eos Trans. AGU 79(45), 661.

Crawford, W. C., S. C. Webb, and J. A. Hildebrand (1991). Seafloor compliance observed by long period pressure and displacement measurements, J. Geophys. Res. 96, 16151-16160.

Friedrich, A., F. Kruger, and K. Klinge (1998). Ocean-generated microseismic noise located with the Graffenberg array, J. Seismol. 2, 4764.

Gutenberg, B. (1931). Microseisms in North America, Bull. Seism. Soc. Am. 21, 1-24.

Hasselmann, K. (1963). A statistical analysis of the generation of microseisms, Rev. Geophys. 1, 177-209.

Hjortenberg, E., and A. N. Nikolaev (Editors) (1990). Microseisms caused by factors internal and external to the earth's crust, Phys. Earth Planet. Interiors 63, 145-283.

IRIS (1995). Federation of Digital Seismograph Networks Station Book, Incorporated Research Institutions for Seismology, Seattle Washington.

Laske, G. (1998). Results from the Hawai SWELL experiment, Eos Trans. $A G U$ 79(45), 662.

Longuet-Higgins, M. S. 1950. A theory of the origin of microseisms, Phil. Trans. Roy. Soc. 243, 1-35.

McCreery, C. S., F. K. Duennebier, and G. H. Sutton (1993). Correlation of deep ocean noise $(0.4-20 \mathrm{~Hz})$ with wind, and the Holu spectrum, a world-wide constant, J. Acoust. Soc. Am. 93, 2639-2648.

Montagner, J. P., B. Romanowicz, and J. F. Karczewski (1994a). A first step towards an Oceanic Geophysical observatory, Eos Trans. AGU 75, 150-154.

Montagner, J. P., J. F. Karczewski, B. Romanowicz, S. Bouaricha, P. Lognonné, G. Roult, E. Stutzmann, J. L. Thirot, D. Fouassier, and J. C. Koenig (1994b). The French pilot experiment OFM/SISMOBS: first scientific results on noise level and event detection, Phys. Earth Planet. Interiors 84, 321-336.

Montagner, J. P., P. Lognonné, R. Beauduin, G. Roult, J. F. Karczewski, and E. Stutzmann (1998). Towards multiscalar and multiparameter networks for the next century: the French efforts, Phys. Earth Planet. Interiors 108, 155-174. 
Morand, M., and G. Roult (1996). GEOSCOPE station book, Institut de Physique du Globe de Paris, Paris, France.

Müller, T., and W. Zürn (1983). Observation of gravity changes during the passage of cold fronts, J. Geophys. 53, 155-162.

Peterson, J. (1993). Observation and modeling of seismic background noise, U.S. Geol. Surv. Tech. Rept. 93-322, 1-95.

Pierson, W. J., and L. Moskowitz (1963). A proposal spectral for fully developed wind seas based on the similarity theory of S. A. Kiaigorodskii, J. Geophys. Res. 69, 5181-5190.

Ramirez, J. E. (1940). An experimental investigation of the nature and origin of microseisms at St. Louis, Missouri, Bull. Seism. Soc. Am. 30, 35-84.

Romanowicz, B., D. Stakes, J. P. Montagner, P. Tarits, R. Urhammer, M. Begnaud, E. Stutzmann, M. Pasyanos, J. F. Karczewski, and S. Etchemendy (1998). MOISE: a pilot experiment towards long-term sea-floor geophysical observatories, Earth Planets Space 50, 927937.

Roult, G., and J. P. Montagner (1999). The GEOSCOPE program: the global $\mathrm{BB}$ and VBB network; data access and new development. ORFEUS Newsletter 1(2), 15.

Roult, G., J. P. Montagner, E. Stutzmann, S. Barbier, and G. Guiveneux (1999). The GEOSCOPE Data Center, Phys. Earth Planet. Interiors $113,25-43$.

Sorrells, G. G. (1971). A preliminary investigation into the relationship between long-period seismic noise and local fluctuations in the atmospheric pressure field, Geophys. J. R. Astr. Soc. 26, 71-82.

Sorrells, G. G., J. A. McDonald, Z. A. Der, and E. Herrin (1971). Earth motion caused by local atmospheric pressure changes, Geophys. J. R. Astr. Soc. 26, 83-98.

Suyehiro, K., T. Kanazawa, N. Hirata, M. Shinohara, and H. Kinoshita
(1992). Broadband downhole digital seismometer experiment at site 794: a technical paper. Proc. ODP, Scientific Results, 127-128.

Thomson, D. J. (1977a). Spectrum estimation techniques for characterisation and development of WT4 waveguide-I, Bell Syst. Tech. J. 56, 1769-1815.

Thomson, D. J. (1977b). Spectrum estimation techniques for characterisation and development of WT4 waveguide-II, Bell Syst. Tech. J. 56, 1983-2005.

Webb, S. C. (1998). Broadband seismology and noise under the ocean, Rev. Geophys. 36, 105-142.

Wielandt, E., and G. Streckeisen (1982). The leaf spring seismometer: design and performance, Bull. Seism. Soc. Am. 72, 2349-2367.

Zürn, W., and R. Widmer (1995). On noise reduction in vertical seismic records below $2 \mathrm{mHz}$ using local barometric pressure, Geophys. Res. Lett. 22, 3537-3540.

Département de Sismologie

Institut de Physique du Globe

4 place Jussieu

75252 Paris-Cedex 05

France

(E. S., G. R.)

IGPP-SIO

9500 Gilman Dr.

La Jolla, California 92093-0225

USA

(L. A.)

Manuscript received 9 March 1999. 


\section{Appendix}
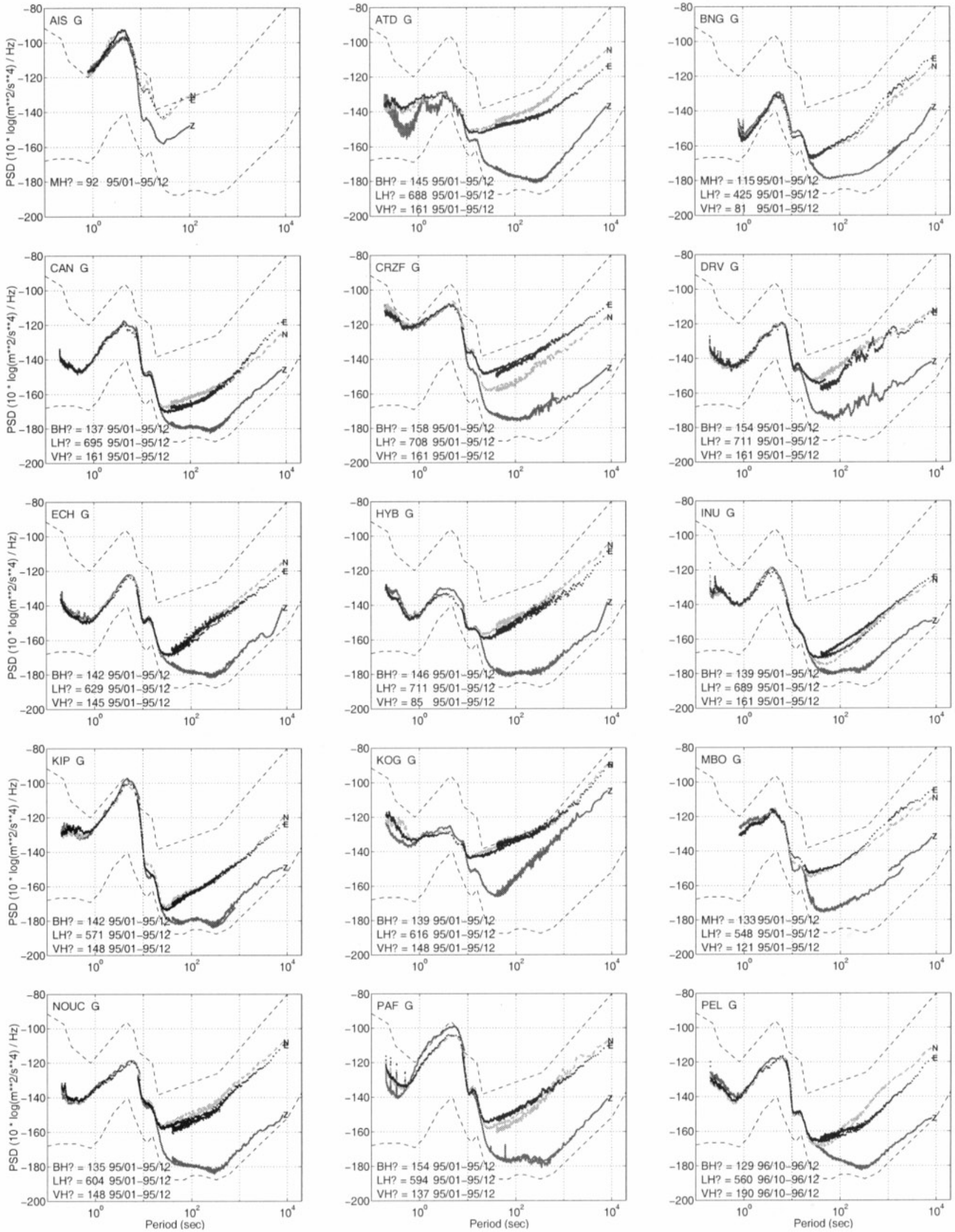

Caption on facing page. 

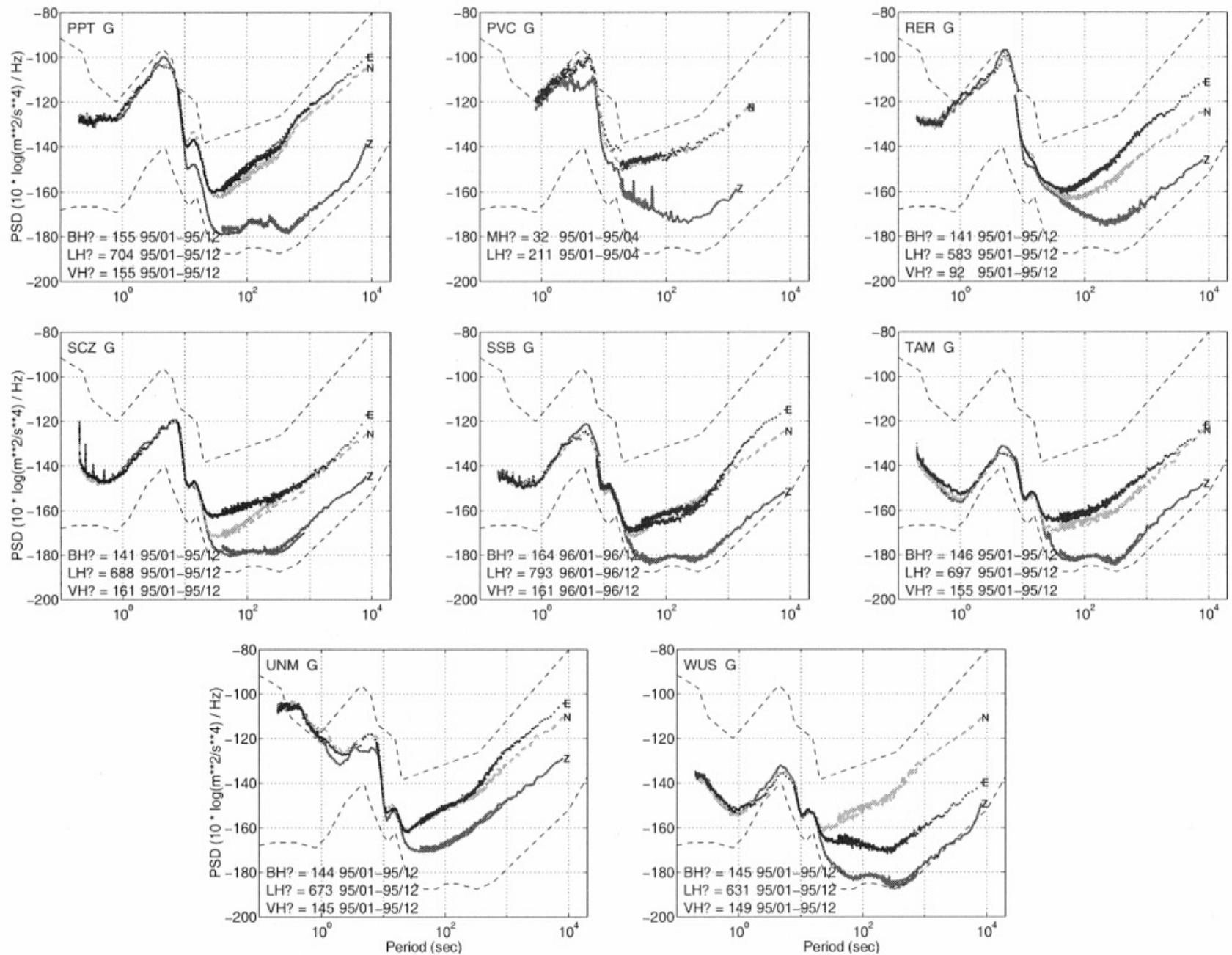

Power spectral density of seismic noise estimated over the year 1995 for all GEOSCOPE station and for the three components, vertical $(Z)$ in dark gray solid line, north-south $(\mathrm{N})$ in light gray dashed line, and east-west in black dotted line. The number of time windows used is written next to the corresponding channel. The lower and upper dash curves are the low (LNM) and high (HNM) noise models of Peterson (1993). 